\title{
Article
}

\section{Sex differences in medial and lateral tibiofemoral compartment loading during different functional sports tasks}

Sinclair, Jonathan Kenneth and Stainton, Philip

Available at http://clok.uclan.ac.uk/31199/

Sinclair, Jonathan Kenneth ORCID: 0000-0002-2231-3732 and Stainton, Philip (2020) Sex differences in medial and lateral tibiofemoral compartment loading during different functional sports tasks. Science \& Sports . ISSN $0765-$ 1597

It is advisable to refer to the publisher's version if you intend to cite from the work. http://dx.doi.org/10.1016/j.scispo.2020.01.001

For more information about UCLan's research in this area go to http://www.uclan.ac.uk/researchgroups/ and search for <name of research Group>.

For information about Research generally at UCLan please go to http://www.uclan.ac.uk/research/

All outputs in CLoK are protected by Intellectual Property Rights law, including Copyright law. Copyright, IPR and Moral Rights for the works on this site are retained by the individual authors and/or other copyright owners. Terms and conditions for use of this material are defined in the policies page. 
Sports

Elsevier Editorial System(tm) for Science \&

Manuscript Draft

Manuscript Number: SCISPO-D-17-00180R1

Title: Sex differences in medial and lateral tibiofemoral compartment loading during different functional sports tasks.

Article Type: Full Length Article

Keywords: Tibiofemoral; sports; biomechanics; pathology

Corresponding Author: Dr. Jonathan Sinclair, PhD, BSc (Hons), Pg Cert, CSCS

Corresponding Author's Institution: University of Central Lancashire

First Author: Jonathan Sinclair, PhD, BSC (Hons), Pg Cert, CSCS

Order of Authors: Jonathan Sinclair, PhD, BSc (Hons), Pg Cert, CSCS; Philip Stainton, MSc

Abstract: Purpose: This study examined sex differences in tibiofemoral compartment loading during sport specific movements.

Materials and methods: Fifteen males and fifteen females completed run and cut motions using an approach velocity of $4.0 \mathrm{~m} . \mathrm{s}-1$. Kinematics were obtained using a motion capture system and kinetics using a force platform. Tibiofemoral compartment loading was quantified using a musculoskeletal simulation approach.

Results: Irrespective of sex or movement the medial tibiofemoral compartment experienced greater peak loading (Male: run medial = 71.32; lateral $=33.49 \mathrm{~N} / \mathrm{kg} /$ cut medial $=69.30 ;$ lateral $=59.17 \mathrm{~N} / \mathrm{kg} \&$ Female: run medial $=73.85 ;$ lateral $=33.61 \mathrm{~N} / \mathrm{kg} /$ cut medial $=69.41 ;$ lateral = $64.03 \mathrm{~N} / \mathrm{kg})$. In addition females were shown to exhibit greater peak medial force per mile $(6381.78 \mathrm{~N} / \mathrm{kg} \cdot \mathrm{s})$ than males $(5139.24 \mathrm{~N} / \mathrm{kg} \cdot \mathrm{s})$ during running. Finally, irrespective of sex, peak lateral force was larger in the cut movement (Male $=59.17 \&$ Female $=64.03 \mathrm{~N} / \mathrm{kg}$ ) compared to the run (Male $=33.49 \&$ Female $=33.61 \mathrm{~N} / \mathrm{kg})$.

Conclusions: This investigation shows that the different facets of the knee are loaded differently during functional athletic movements but also that both sex and the movement being executed may also be important. Specifically, female runners appear to be at increased risk of medial knee degeneration linked to the aetiology of osteoarthritis.

Objectif: Cette étude a examiné les différences liées au sexe dans compartiment tibiofémorale, chargement durant les mouvements particuliers de sport.

Matériels et méthodes: quinze hommes et quinze femmes terminées exécutez et couper des requêtes en utilisant une vitesse d'approche de $4.0 \mathrm{~m} . \mathrm{s}-1$. Cinématique ont été obtenues à l'aide d'un système de capture de mouvement et de la cinétique à l'aide d'une plateforme de force. Chargement de compartiment de tibiofémorale a été quantifiée à l'aide d'une approche de simulation musculo-squelettiques. 
Résultats: Sans distinction de sexe ou de mouvement le compartiment médial tibiofémorale a connu une plus grande charge de crête (mâle : exécutez médial $=71.32 ;$ latéral $=33.49 \mathrm{~N} / \mathrm{kg} /$ cut médial $=69.30$; latéral $=\mathrm{N} / \mathrm{kg} 59.17$ \& femelle: exécuter médial $=73.85$; latéral $=$ $33.61 \mathrm{~N} / \mathrm{kg} /$ cut médial $=69.41$; latéral $=64.03 \mathrm{~N} / \mathrm{kg})$. En outre femelles ont montré d'exposer une plus grande force médiale maximale par mille $(6381.78 \mathrm{~N} / \mathrm{kg} \cdot \mathrm{s})$ que les mâles $(5139.24 \mathrm{~N} / \mathrm{kg} \cdot \mathrm{s})$ au cours de la course. Enfin, indépendamment du sexe, la force latérale maximale était plus importante dans le mouvement de coupe (mâle $=59.17$ \& femelle = $64.03 \mathrm{~N} / \mathrm{kg}$ ) par rapport à la course (mâle $=33.49$ \& femelle $=33.61 \mathrm{~N} / \mathrm{kg}$ ). Conclusions: Cette étude montre que les différentes facettes du genou sont chargés différemment au cours de mouvements athlétiques fonctionnels mais aussi que les sexe et le mouvement en cours d'exécution peuvent aussi être importants. Plus précisément, les coureurs féminins semblent être à un risque accru de dégénérescence médial genou lié à l'étiologie de l'arthrose. 
Reviewer \#1: General comments.

This manuscript is informative, concise and well written. Specific comments are minor and relate to questions in the introduction, methods and discussion.

We thank the reviewer for giving a thorough review of our paper and for their thoughtful comments in regards to our manuscript.

Specific comments.

Introduction - Clear and logical flow of the text that leads to a specific aim. Can the authors provide further context on musculoskeletal models and provide an example of its applications to assess loading?

RESPONSE: Further detail regarding the necessity of musculoskeletal simulation is now added to this section.

Also, can the authors provide an overview on what is currently known on knee loading during dynamic movements?

RESPONSE: This is now added to the introduction section of the paper.

Materials and methods - Can the authors provide a justification for 4.0 m.s-1 since approach velocity will influence loading. What was the reason for focusing on the dominant limb since lower limb kinematics on the dominant limb, particularly in female athletes, have been shown to differ compared with the non-dominant limb?

RESPONSE: Justification for the adopted approach velocity has now been added to the paper in the form a of a citation from previous literature concerning knee joint kinetics during the cut movement. These approach velocities have been adopted for these specific movements consistently in biomechanics literature - thus adopting the current approach provides a solid basis in the literature and provides context in relation to a significant volume of existing literature.

The dominant limb was selected again to be consistent with previous literature concerning knee loads during dynamic movements - however we do acknowledge this a potential limitation and have added to this in the discussion.

Results - Detailed and well written section.

RESPONSE: Thank you.

Discussion - Clear, concise and well written section. 
RESPONSE: Thank you. 


\section{$\underline{\text { Sex differences in medial and lateral tibiofemoral compartment loading during different }}$}

\section{functional sports tasks.}

Jonathan Sinclair ${ }^{1} \&$ Philip Stainton ${ }^{1}$

1. Centre for Applied Sport and Exercise Sciences, School of Sport and Wellbeing, Faculty of Health \& Wellbeing, University of Central Lancashire, Lancashire, UK.

\section{Correspondence Address:}

Dr. Jonathan Sinclair,

Darwin Building

Centre for Applied Sport \& Exercise Sciences

School of Sport and Wellbeing,

Faculty of Health \& Wellbeing,

University of Central Lancashire,

Preston

Lancashire

PR1 2HE.

e-mail: jksinclair@uclan.ac.uk

Keywords: Tibiofemoral; sports; biomechanics; pathology. 


\title{
$\underline{\text { Sex differences in medial and lateral tibiofemoral compartment loading during different }}$
}

\author{
functional sports tasks.
}

\section{Différences entre les sexes dans compartiment médial et latéral tibiofémorale \\ chargement durant des tâches fonctionnelles de différents sports.}

Keywords: Tibiofemoral; sports; biomechanics; pathology.

\begin{abstract}
Purpose: This study examined sex differences in tibiofemoral compartment loading during sport specific movements.
\end{abstract}

Materials and methods: Fifteen males and fifteen females completed run and cut motions using an approach velocity of $4.0 \mathrm{~m} . \mathrm{s}^{-1}$. Kinematics were obtained using a motion capture system and kinetics using a force platform. Tibiofemoral compartment loading was quantified using a musculoskeletal simulation approach.

Results: Irrespective of sex or movement the medial tibiofemoral compartment experienced greater peak loading $($ Male: run medial $=71.32 ;$ lateral $=33.49 \mathrm{~N} / \mathrm{kg} /$ cut medial $=69.30$; lateral $=59.17 \mathrm{~N} / \mathrm{kg} \&$ Female: run medial $=73.85 ;$ lateral $=33.61 \mathrm{~N} / \mathrm{kg} /$ cut medial = 69.41; lateral $=64.03 \mathrm{~N} / \mathrm{kg}$ ). In addition females were shown to exhibit greater peak medial force per mile $(6381.78 \mathrm{~N} / \mathrm{kg} \cdot \mathrm{s})$ than males $(5139.24 \mathrm{~N} / \mathrm{kg} \cdot \mathrm{s})$ during running. Finally, irrespective of sex, peak lateral force was larger in the cut movement $($ Male $=59.17 \&$ Female $=64.03 \mathrm{~N} / \mathrm{kg})$ compared to the run $($ Male $=33.49 \&$ Female $=33.61 \mathrm{~N} / \mathrm{kg})$.

Conclusions: This investigation shows that the different facets of the knee are loaded differently during functional athletic movements but also that both sex and the movement being executed may also be important. Specifically, female runners appear to be at increased risk of medial knee degeneration linked to the aetiology of osteoarthritis. 
Objectif: Cette étude a examiné les différences liées au sexe dans compartiment tibiofémorale, chargement durant les mouvements particuliers de sport.

Matériels et méthodes: quinze hommes et quinze femmes terminées exécutez et couper des requêtes en utilisant une vitesse d'approche de $4.0 \mathrm{~m} \cdot \mathrm{s}^{-1}$. Cinématique ont été obtenues à l'aide d'un système de capture de mouvement et de la cinétique à l'aide d'une plateforme de force. Chargement de compartiment de tibiofémorale a été quantifiée à l'aide d'une approche de simulation musculo-squelettiques.

Résultats: Sans distinction de sexe ou de mouvement le compartiment médial tibiofémorale a connu une plus grande charge de crête (mâle $:$ exécutez médial $=71.32$; latéral $=33.49 \mathrm{~N} / \mathrm{kg}$ / cut médial $=69.30 ;$ latéral $=\mathrm{N} / \mathrm{kg} 59.17 \&$ femelle: exécuter médial $=73.85 ;$ latéral $=$ $33.61 \mathrm{~N} / \mathrm{kg} /$ cut médial $=69.41$; latéral $=64.03 \mathrm{~N} / \mathrm{kg}$ ). En outre femelles ont montré d'exposer une plus grande force médiale maximale par mille $(6381.78 \mathrm{~N} / \mathrm{kg} \cdot \mathrm{s})$ que les mâles $(5139.24 \mathrm{~N} / \mathrm{kg} \cdot \mathrm{s})$ au cours de la course. Enfin, indépendamment du sexe, la force latérale maximale était plus importante dans le mouvement de coupe $($ mâle $=59.17 \&$ femelle $=$ $64.03 \mathrm{~N} / \mathrm{kg}$ ) par rapport à la course (mâle $=33.49 \&$ femelle $=33.61 \mathrm{~N} / \mathrm{kg}$ ).

Conclusions: Cette étude montre que les différentes facettes du genou sont chargés différemment au cours de mouvements athlétiques fonctionnels mais aussi que les sexe et le mouvement en cours d'exécution peuvent aussi être importants. Plus précisément, les coureurs féminins semblent être à un risque accru de dégénérescence médial genou lié à l'étiologie de l'arthrose.

\section{Introduction}

There is an overwhelming body of evidence which has emphasized the physiological and psychological benefits of physical activity and exercise (1). Physical inactivity is regarded as 
a modifiable risk factor for cardiovascular disease and a range of other enduring pathologies such as diabetes mellitus type 2, cancer, hypertension and depression (2). As such there are global initiatives which strive to encourage the adoption of a physically active lifestyle (3). However despite the conclusive health benefits associated with regular physical activity, it is also known to be associated with a high incidence of injury (4). Injury is considered the only disadvantage associated with regular exercise, but is unfortunately known to be a common complaint linked with substantial issues (4). Treatment of injuries related to physical activity is challenging for both patients and clinicians, and places economic demands on the global healthcare system (5).

Osteoarthritis (OA) is one of the leading global causes of disability (6). It is the most common progressive joint pathology and affects $13.9 \%$ of adults aged 25 and older and as many as $35 \%$ of those over the age of 65 (7). The knee is the most common anatomical location for the initiation and progression of osteoarthritic symptoms (8), and the pain and stiffness that accompany knee OA inhibit daily activities (9). In addition to reducing quality of life, knee OA is also a significant economic encumbrance; with lifetime treatment costs for patients with knee OA being $\$ 140,300$ (10). Importantly, aetiological research has linked involvement in physical activity with the initiation of osteoarthritic symptoms at the knee (11). Dynamic activities that involve running, changing direction and jumping impart high loads to the knee joint (12), but it is currently not clear as to whether specific sports movements/ tasks increase the risk for knee OA initiation/ progression.

Females are known to be at increased risk from knee OA in comparison to males, with a ratio as high as 4:1 (13). Females have also been shown to be affected more punitively by knee OA in terms of severity of their degenerative symptoms (14) and the presentation of pain indices 
associated with their condition (15). Experimental findings have shown that OA may also affect different anatomical aspects of the knee differently in females in relation to males (16). The mechanisms responsible for the increased prevalence and potentially distinct presentation of $\mathrm{OA}$ in females is not properly established; however high contact stress is considered as the most important mechanical factor linked to the aetiology of knee OA (7).

Previous analyses examining sex differences in tibiofemoral joint loading, have utilized joint torques of musculoskeletal modelling approaches to explore the knee joint loads. Herzog et al., (17) have however shown that showed that the muscles are the main contributors musculoskeletal joint loading. Until recently, due to difficulties associated with calculating muscle kinetics, the non-invasive quantification of contact loading at the different aspects of the knee was not possible. However, the advancement of musculoskeletal simulation based algorithms and software have advanced to the point where accurate and reliable estimates of loading patterns at the different anatomical aspects of the knee are now available.

Despite the relative novelty of musculoskeletal simulation analyses, a limited number of scientific analyses have examined the magnitude of the loads experienced by the distinct aspects of the tibiofemoral joint during dynamic tasks. Sinclair et al., (18) showed that peak medial tibiofemoral forces were $6.23 \mathrm{BW}$ and $6.53 \mathrm{BW}$ and lateral tibiofemoral forces were 3.94BW and 4.17BW during shod and barefoot running respectively. Esculier et al., (19) found that peak medial tibiofemoral forces were $2.6 \mathrm{BW}$ and $6.2 \mathrm{BW}$ during walking and running tasks in males and females. However, although musculoskeletal simulation analyses of the tibiofemoral joint have been initiated in biomechanical literature, there has yet to be an investigation which has examined the loads experienced by the different aspects of this joint during both running and cutting in male and females. 


\section{Therefore, the aim of the current study was to examine sex differences in medial and lateral}

tibiofemoral compartment loading during these sport specific movements. This work may generate clinically meaningful information regarding the susceptibility of male and female athletes to arthritic degeneration at the different anatomical aspects of the knee and provide further insight into the aetiology of knee OA in females.

\section{Materials and Methods}

\subsection{Participants}

Fifteen male (age $24.4 \pm 3.7$ years, height $1.78 \pm 0.11 \mathrm{~m}$ and body mass $74.3 \pm 5.4 \mathrm{~kg}$ ) and fifteen female (age $23.9 \pm 3.8$ years, height $1.65 \pm 0.09 \mathrm{~m}$ and body mass $65.2 \pm 5.8 \mathrm{~kg}$ ) recreational athletes volunteered to take part in the current investigation. All participants were free from lower extremity musculoskeletal pathology at the time of data collection. All provided written informed consent and ethical approval was obtained from the University of Central Lancashire, in accordance with the principles documented in the declaration of Helsinki.

\subsection{Procedure}

Participants completed five repeats of two sport specific movements; run and cut. To control for any order effects the order in which participants performed in each movement condition were counterbalanced. Kinematic information from the lower extremity joints was obtained using an eight camera motion capture system (Qualisys Medical AB, Goteburg, Sweden) using a capture frequency of $250 \mathrm{~Hz}$. To measure kinetic information an embedded piezoelectric force platform (Kistler National Instruments, Model 9281CA) operating at 1000 
$\mathrm{Hz}$ was utilized. The kinetic and kinematic information were synchronously obtained and interfaced using Qualisys track manager.

To define the anatomical frames of the thorax, pelvis, thighs, shanks and feet retroreflective markers were placed at the $\mathrm{C} 7, \mathrm{~T} 12$ and xiphoid process landmarks and also positioned bilaterally onto the acromion process, iliac crest, anterior superior iliac spine (ASIS), posterior super iliac spine (PSIS), medial and lateral malleoli, medial and lateral femoral epicondyles, greater trochanter, calcaneus, first metatarsal and fifth metatarsal. Carbon-fibre tracking clusters comprising of four non-linear retroreflective markers were positioned onto the thigh and shank segments. In addition to these the foot segments were tracked via the calcaneus, first metatarsal and fifth metatarsal, the pelvic segment was tracked using the PSIS and ASIS markers and the thorax segment was tracked using the T12, C7 and xiphoid markers. Static calibration trials were obtained with the participant in the anatomical position in order for the positions of the anatomical markers to be referenced in relation to the tracking clusters/markers. A static trial was conducted with the participant in the anatomical position in order for the anatomical positions to be referenced in relation to the tracking markers, following which those not required for dynamic data were removed.

Data were collected during the run and cut movements according to below procedures:

Run

Participants ran at $4.0 \mathrm{~m} . \mathrm{s}^{-1} \pm 5 \%$ and struck the force platform with their right (dominant) limb (20). The average velocity of running was monitored using infra-red timing gates (SmartSpeed Ltd UK). The stance phase of running was defined as the duration over $>20 \mathrm{~N}$ of vertical force was applied to the force platform (21). 


\section{Cut}

Participants completed $45^{\circ}$ sideways cut movements using an approach velocity of $4.0 \mathrm{~m} . \mathrm{s}^{-1}$ $\pm 5 \%$ striking the force platform with their right (dominant) limb (20). In accordance with McLean et al., (22) cut angles were measured from the centre of the force plate and the corresponding line of movement was delineated using masking tape so that it was clearly evident to participants. The stance phase of the cut-movement was similarly defined as the duration over $>20 \mathrm{~N}$ of vertical force was applied to the force platform (21).

\subsection{Processing}

Dynamic trials were digitized using Qualisys Track Manager in order to identify anatomical and tracking markers then exported as C3D files to Visual 3D (C-Motion, Germantown, MD, USA). Data during the stance phase were exported from Visual 3D into OpenSim 3.3 software (Simtk.org). A validated musculoskeletal model with 12 segments, 19 degrees of freedom and 92 musculotendon actuators (23) was used to estimate medial and lateral tibiofemoral forces. The model was scaled for each participant to account for the anthropometrics of each athlete. As muscle forces are the main determinant of tibiofemoral compressive forces (24), muscle kinetics were quantified using a static optimization in accordance with Steele et al., (25). Medial and lateral tibiofemoral contact forces were calculated via the joint reaction analyses function using the muscle forces generated from the static optimization process as inputs. From the above processing, peak medial force, peak lateral force, medial/lateral average load rate, medial/lateral instantaneous load rate and medial/lateral force integral were extracted for statistical analysis. 


\subsection{Analyses}

Descriptive statistics of means, standard deviations (SD) and 95\% confidence intervals (95\% CI) were obtained for each outcome measure. Shapiro-Wilk tests were used to screen the data for normality. Differences in tibiofemoral loading parameters at the different sides of the knee (medial/ lateral) were examined using 2 (sex) *2 (movement) *2 (side) mixed ANOVA's. Tibiofemoral force per mile was examined using 2 (sex) *2 (side) mixed ANOVA's and sex differences in stride characteristics were explored using independent samples t-tests. Main effects were examined using post-hoc pairwise comparisons and interactions were explored using simple main effects. Statistical significance was accepted at the $\mathrm{P}<0.05$ level (28). Effect sizes for all significant findings were calculated using partial 
$\operatorname{Eta}^{2}\left(\mathrm{p \eta}^{2}\right)$. All statistical actions were conducted using SPSS v22.0 (SPSS Inc, Chicago, USA).

\title{
3. Results
}

Tables 1-3 and Figure 1 shows the differences in medial and lateral tibiofemoral joint loading as a function of sex, movement and side. The findings from this investigation confirm that tibiofemoral loading was significantly influenced by the experimental conditions.

\author{
@@@ Figure 1 near here@@@ \\ @@@Table1near here@@@ \\ @@ Table 2 near here @@@ \\ @@ Table 3 near here @ @ @
}

\subsection{Tibiofemoral compartment loads}

For peak force a main effect was revealed for side $\left(\mathrm{F}_{(1,28)}=166.57, \mathrm{P}<0.05, \mathrm{p \eta}^{2}=0.86\right)$, which showed that the medial aspect of the tibiofemoral joint was loaded to a greater extent than the lateral compartment. A main effect was also evident for movement $\left(\mathrm{F}_{(1,28)}=19.90\right.$, $\mathrm{P}<0.05, \mathrm{p} \eta^{2}=0.42$ ), this showed that the cut movement was associated with increased tibiofemoral loading in relation to the run condition. Finally, a side * movement interaction was also apparent $\left(\mathrm{F}_{(1,28)}=49.24, \mathrm{P}<0.05, \mathrm{p \eta}^{2}=0.64\right)$. Follow up analyses using simple main effects showed that the medial tibiofemoral compartment experienced greater loading in both the run $\left(\mathrm{F}_{(1,29)}=198.23, \mathrm{P}<0.05, \mathrm{p \eta}^{2}=0.87\right)$ and cut $\left(\mathrm{F}_{(1,29)}=7.08, \mathrm{P}<0.05, \mathrm{p \eta}^{2}=0.20\right)$ movements. In addition, it was revealed that there was no difference between movements for the medial compartment $\left(\mathrm{F}_{(1,29)}=0.70, \mathrm{P}<0.05, \mathrm{p \eta}^{2}=0.02\right)$ but the lateral tibiofemoral 
compartment was loaded to a greater extent $\left(\mathrm{F}_{(1,29)}=78.19, \mathrm{P}<0.05, \mathrm{p \eta}^{2}=0.73\right)$ in the cut movement compared to the run (Table 1; Figure 1).

For average load rate a main effect was revealed for side $\left(\mathrm{F}_{(1,28)}=62.20, \mathrm{P}<0.05, \mathrm{p \eta}^{2}=\right.$ 0.69), which showed that the medial aspect of the tibiofemoral joint experienced a greater loading rate in comparison to the lateral aspect. Finally, a side * movement interaction was also apparent $\left(\mathrm{F}_{(1,28)}=8.37, \mathrm{P}<0.05, \mathrm{p \eta}^{2}=0.23\right)$. Follow up analyses using simple main effects showed that the medial tibiofemoral compartment experienced greater loading in both the run $\left(\mathrm{F}_{(1,29)}=36.33, \mathrm{P}<0.05, \mathrm{p \eta}^{2}=0.56\right)$ and $\operatorname{cut}\left(\mathrm{F}_{(1,29)}=12.11, \mathrm{P}<0.05, \mathrm{p \eta}^{2}=0.30\right)$ movements. In addition, it was revealed that there was no difference between movements for the medial compartment $\left(\mathrm{F}_{(1,29)}=1.64, \mathrm{P}<0.05, \mathrm{p \eta}^{2}=0.05\right)$ but the lateral tibiofemoral compartment was loaded to a greater extent $\left(\mathrm{F}_{(1,29)}=16.06, \mathrm{P}<0.05, \mathrm{p \eta}^{2}=0.36\right)$ in the cut movement compared to the run (Table 1).

For instantaneous load rate a main effect was revealed for side $\left(\mathrm{F}_{(1,28)}=62.38, \mathrm{P}<0.05, \mathrm{p}^{2}=\right.$ 0.70), which showed that the medial aspect of the tibiofemoral joint experienced a greater loading rate in comparison to the lateral aspect. Finally, a side * movement interaction was also apparent $\left(\mathrm{F}_{(1,28)}=12.28, \mathrm{P}<0.05, \mathrm{p \eta}^{2}=0.31\right)$. Follow up analyses using simple main effects showed that the medial tibiofemoral compartment experienced greater loading in both the run $\left(\mathrm{F}_{(1,29)}=56.27, \mathrm{P}<0.05, \mathrm{p \eta}^{2}=0.66\right)$ and cut $\left(\mathrm{F}_{(1,29)}=10.56, \mathrm{P}<0.05, \mathrm{p \eta}^{2}=0.27\right)$ movements. In addition, it was revealed that there was no difference between movements for the medial compartment $\left(\mathrm{F}_{(1,29)}=0.95, \mathrm{P}<0.05, \mathrm{p}^{2}=0.03\right)$ but the lateral tibiofemoral compartment was loaded to a greater extent $\left(\mathrm{F}_{(1,29)}=29.74, \mathrm{P}<0.05, \mathrm{p \eta}^{2}=0.51\right)$ in the cut movement compared to the run (Table 1). 
For the tibiofemoral force integral a main effect was revealed for side $\left(\mathrm{F}_{(1,28)}=182.25\right.$, $\mathrm{P}<0.05, \mathrm{p \eta}^{2}=0.87$ ), which showed that the medial aspect of the tibiofemoral joint experienced a greater impulse than the lateral compartment. A main effect was also evident for movement $\left(\mathrm{F}_{(1,28)}=27.26, \mathrm{P}<0.05, \mathrm{p \eta}^{2}=0.49\right)$, this showed that the cut movement was associated with increased tibiofemoral impulse in relation to the run condition. Finally, a side

* movement interaction was also apparent $\left(\mathrm{F}_{(1,28)}=52.48, \mathrm{P}<0.05, \mathrm{p}^{2}=0.65\right)$. Follow up analyses using simple main effects showed that the medial tibiofemoral compartment experienced greater loading in both the run $\left(\mathrm{F}_{(1,29)}=268.46, \mathrm{P}<0.05, \mathrm{p}^{2}=0.90\right)$ and cut $(\mathrm{F}$ $\left.(1,29)=6.08, \mathrm{P}<0.05, \mathrm{p \eta}^{2}=0.17\right)$ movements. In addition, it was revealed that there was no difference between movements for the medial compartment $\left(\mathrm{F}_{(1,29)}=0.30, \mathrm{P}<0.05, \mathrm{p} \eta^{2}=\right.$ $0.01)$ but the lateral tibiofemoral compartment was loaded to a greater extent $\left(\mathrm{F}_{(1,29)}=75.33\right.$, $\left.\mathrm{P}<0.05, \mathrm{p} \eta^{2}=0.72\right)$ in the cut movement compared to the run (Table 1).

\subsection{Stride characteristics}

Males were found to exhibit a longer stride length $\left(\mathrm{t}{ }_{(28)}=7.95, \mathrm{P}<0.05\right)$ in comparison to females. In addition males also required a significantly reduced number of strides to complete one mile $\left(\mathrm{t}_{(28)}=7.81, \mathrm{P}<0.05\right)$ compared to females (Table 2$)$.

\subsection{Tibiofemoral loads per mile}

A main effect was observed for side $\left(\mathrm{F}_{(1,28)}=283.22, \mathrm{P}<0.05, \mathrm{p}^{2}=0.91\right)$, this revealed that force experienced per mile was significantly larger at the medial side in relation to the lateral tibiofemoral compartment. In addition there was also a main effect of $\operatorname{sex}\left(\mathrm{F}_{(1,28)}=4.21\right.$, $\left.\mathrm{P}<0.05, \mathrm{p} \eta^{2}=0.14\right)$ which showed that females exhibit larger loading in comparison to males. Finally there was a significant side $*$ sex interaction $\left(\mathrm{F}_{(1,28)}=4.66, \mathrm{P}<0.05, \mathrm{p} \eta^{2}=0.15\right)$. Follow up analyses using simple main effects showed that both males $\left(F_{(1,14)}=95.79\right.$, 
$\left.\mathrm{P}<0.05, \mathrm{p}^{2}=0.87\right)$ and females $\left(\mathrm{F}_{(1,14)}=205.64, \mathrm{P}<0.05, \mathrm{p}^{2}=0.94\right)$ experienced increased loading at the medial tibiofemoral compartment. In addition simple main effects showed that at the medial tibiofemoral compartment females exhibited larger $\left(\mathrm{F}_{(1,14)}=5.64, \mathrm{P}<0.05, \mathrm{p} \eta^{2}\right.$ $=0.17)$ loading in comparison to males but no difference $\left(\mathrm{F}_{(1,14)}=1.17, \mathrm{P}>0.05, \mathrm{p} \eta^{2}=0.04\right)$ was apparent at the lateral compartment (Table 3).

\section{Discussion}

The aim of this investigation was to examine sex differences in medial and lateral tibiofemoral compartment loading when performing sport specific movements. To the authors knowledge this represents the first comparative analysis which has considered the effects of both sex and movement on the loading characteristics of the different aspects of the tibiofemoral joint. Research of this nature may help to generate important information regarding the susceptibility of different genders to $\mathrm{OA}$ at the different anatomical aspects of the knee and also in regards to the increased incidence of knee OA in females.

The first key observation from the current analysis was that irrespective of movement and sex, medial compartment loads were shown to be significantly larger than those experienced at the lateral aspect of the tibiofemoral joint. The mechanical aetiology of knee OA is considered to be linked with high contact stresses at the tibiofemoral joint itself (7). Therefore, the findings from this observation support and build upon the findings of Dearborn et al., (29); indicating that the medial aspect of the knee may be more susceptible to OA as a function of the specific athletic tasks examined here.

In addition to this the current investigation also confirmed the observations of previous analyses (26), which have demonstrated that females exhibit a reduced step length during 
running in relation to males. This consequently requires females to utilize a significantly larger number of footfalls to complete a predetermined running distance. Previous work investigating sex differences in knee forces have examined only the loads experienced for each individual footfall $(30,31)$. Importantly whilst the current investigation revealed no sex differences in tibiofemoral forces per footfall, cumulative medial tibiofemoral compartment loads were found to be significantly larger in females. This finding is therefore in agreement with the observations of Hanna et al., (16) which indicate that knee OA in females may be expressed distinctively and may influence certain aspects of the knee joint differently. This finding may also have clinical relevance regarding the initiation and progression of knee OA. The mechanism by which knee OA symptoms initiate is considered to be repeated high loads imposed too frequently to the tibiofemoral joint itself (7). Therefore the findings from the current work agree with those of Hame and Alexander, (13) and Sangha et al., (32) and suggest that females who engage in regular running activities may be at increased risk from developing medial compartment $\mathrm{OA}$ in relation to males.

Of further importance is the observation that the cut movement was associated with significantly larger lateral compartment loading in comparison to the run condition. This observation is in agreement with the findings of Saxby et al., (33) who also demonstrated that lateral compartment loading was greater during a $45^{\circ}$ cut movement compared to running. It is proposed that this finding is caused by the distinct biomechanics of the cut movement in relation to the run whereby the resultant knee external moment would have concentrated contact loading at the lateral component to a greater extent than in the run condition. The key implication from this finding is that different functional athletic movements influence loading at the specific tibiofemoral compartments. Although knee OA affects the medial tibiofemoral compartment more poignantly (due to the increased degree of loading at the medial 
compartment) (34), the aforementioned association between tibiofemoral loading and the aetiology of osteoarthritic degeneration (7), indicates that the cut movement may place the lateral tibiofemoral component at greater risk from degeneration. However, due to the noncyclical nature of cutting maneuvers in comparison to running, further epidemiological analyses are required to determine whether sports that require which require frequent cutting actions are associated with a higher incidence of lateral tibiofemoral pathologies.

A potential limitation to the current analysis is that only the dominant limb was explored during the stance phase of the run and cut movements. Previous analyses have shown that athletes may be at greater risk from tibiofemoral osteoarthritis in the non-dominant limb (35), therefore it is strongly recommended that future analyses consider bilateral approaches when quantifying tibiofemoral loads during human movement.

\section{Conclusion}

In conclusion, although biomechanical differences in knee joint mechanics between males and females have been investigated previously, current knowledge regarding differences in tibiofemoral compartment loading during functional athletic tasks is lacking. This study consequently adds to the current literature base in the field of clinical biomechanics and bioengineering by presenting a comprehensive examination of sex differences in tibiofemoral compartment loading during two athletic tasks. The findings from current work show firstly that the medial aspect of the tibiofemoral joint experiences greater loading. In addition, this study also showed that lateral tibiofemoral loading was larger during the cut movement. Notably, it was also revealed that female runners appear to be at increased risk of medial tibiofemoral compartment loading linked to the aetiology of OA. 


\section{Acknowledgments}

We thank Gareth Shadwell for his technical assistance.

\section{Conflict of interest}

None to declare.

\section{References}

1. Warburton DE, Nicol CW, Bredin SS. Health benefits of physical activity: the evidence. Can. Med. Assoc. J; 2009: 174, 801-809.

2. Blair SN, Brodney S. Effects of physical inactivity and obesity on morbidity and mortality: current evidence and research issues. Med Sci Sport Exerc; 1999: 31, 646662.

3. Blair SN, LaMonte, MJ, Nichaman MZ. The evolution of physical activity recommendations: how much is enough?. Am J Clin Nutr; 2004: 79, 913-920.

4. Lauersen JB, Bertelsen DM, Andersen LB. The effectiveness of exercise interventions to prevent sports injuries: a systematic review and meta-analysis of randomised controlled trials. Br J Sports Med; 2014: 48, 871-877.

5. Khan KM, Thompson AM, Blair SN, Sallis JF, Powell KE, Bull FC, Bauman AE. Sport and exercise as contributors to the health of nations. Lancet; 2012: 380, 59-64.

6. Altman RD. Early management of osteoarthritis. Am J Manag Care; 2010: 16, 41-47.

7. Boyan BD, Tosi LL, Coutts RD, Enoka RM, Hart DA, Nicolella DP, Kohrt WM. Addressing the gaps: sex differences in osteoarthritis of the knee. Biol Sex Differ (Epub ahead of print), 2013

8. Heidari B. Knee osteoarthritis prevalence, risk factors, pathogenesis and features: Part I. Caspian J Intern Med; 2011: 2, 205-212. 
9. Sims EL, Carland JM, Keefe FJ, Kraus VB, Guilak F, Schmitt D. Sex differences in biomechanics associated with knee osteoarthritis. J. Women Aging; 2009: 21:159170.

10. Losina E, Paltiel AD, Weinstein AM, Yelin E, Hunter DJ, Chen SP, Walensky RP. Lifetime medical costs of knee osteoarthritis management in the United States: impact of extending indications for total knee arthroplasty. Arthritis Care Res; 2015: 67, 203 215.

11. Cheng Y, Macera CA, Davis DR, Ainsworth BE, Troped PJ, Blair SN. Physical activity and self-reported, physician-diagnosed osteoarthritis: is physical activity a risk factor?. J Clin Epidemiol; 2000: 53, 315-322.

12. Driban JB, Hootman JM, Sitler MR, Harris K, Cattano NM. Is participation in certain sports associated with knee osteoarthritis? A systematic review. J Athl Train, (Epub ahead of print), 2015.

13. Hame SL, Alexander RA. Knee osteoarthritis in women. Curr Rev Musculoskelet Med; 2013: 6, 182-187.

14. Debi R, Mor A, Segal O, Segal G, Debbi E, Agar G, Elbaz A. Differences in gait patterns, pain, function and quality of life between males and females with knee osteoarthritis: a clinical trial. BMC Musculoskelet Disord; 2009: 10, 1-8.

15. O'Connor MI. Sex differences in osteoarthritis of the hip and knee. J Am Acad Orthop Surg; 2007: 15, 22-25.

16. Hanna FS, Teichtahl AJ, Wluka AE, Wang Y, Urquhart DM, English DR, Cicuttini, FM. Women have increased rates of cartilage loss and progression of cartilage defects at the knee than men: a gender study of adults without clinical knee osteoarthritis. Menopause; 2009: 16, 666-670. 
17. Herzog W, Clark A, Wu J. Resultant and local loading in models of joint disease. Arthritis Care Res; 2003: 49, 239-247.

18. Sinclair, J. Effects of barefoot and shod running on lower extremity joint loading, a musculoskeletal simulation study. Sport Sci Health; (In press https://doi.org/10.1007/s1133).

19. Esculier JF, Willy RW, Baggaley MW, Meardon SA, Willson JD. Sex-specific kinetic and kinematic indicators of medial tibiofemoral force during walking and running. The Knee; 2017: 24, 1317-1325.

20. Sinclair JK, Selfe J, Taylor PJ, Shore HF, Richards JD. Influence of a knee brace intervention on perceived pain and patellofemoral loading in recreational athletes. Clin Biomech; 2016: 37, 7-12.

21. Sinclair J, Hobbs SJ, Protheroe L, Edmundson CJ, Greenhalgh A. Determination of gait events using an externally mounted shank accelerometer. J App Biomech; 2013: 29, 118-122.

22. McLean SG, Huang X, Su A, Van Den Bogert AJ. Sagittal plane biomechanics cannot injure the ACL during sidestep cutting. Clin Biomech; 2004; 19, 828-838.

23. Lerner ZF, DeMers MS, Delp SL, Browning RC. How tibiofemoral alignment and contact locations affect predictions of medial and lateral tibiofemoral contact forces. $\mathrm{J}$ Biomech; 2015: 48, 644-650.

24. Herzog W, Longino D, Clark A. The role of muscles in joint adaptation and degeneration. Langenbecks Arch Surg; 2003: 388, 305-315.

25. Steele KM, DeMers MS, Schwartz MH, Delp SL. Compressive tibiofemoral force during crouch gait. Gait Posture; 2012: 35, 556-560.

26. Elliott BC, Blanksby BA. Optimal stride length considerations for male and female recreational runners. Br J Sports Med; 1979: 13, 15-18. 
27. Almonroeder T, Willson JD, Kernozek TW. The effect of foot strike pattern on Achilles tendon load during running. Ann Biomed Eng; 2013: 41, 1758-1766.

28. Sinclair J, Taylor PJ, Hobbs SJ. Alpha level adjustments for multiple dependent variable analyses and their applicability-a review. Int J Sport Sci Eng; 2013: 7, 17-20.

29. Dearborn JT, Eakin CL, Skinner HB. Medial compartment arthrosis of the knee. Am J Orthop; 1996: 25, 18-26.

30. Sinclair J, Selfe J. Sex differences in knee loading in recreational runners. J Biomech; 2015: 48, 2171-2175.

31. Almonroeder TG, Benson LC. Sex differences in lower extremity kinematics and patellofemoral kinetics during running. J Sport Sci; 2016: 28, 1-7.

32. Sangha O. Epidemiology of rheumatic diseases. Rheumatology; 2000: 39, 3-12.

33. Saxby DJ, Modenese L, Bryant AL, Gerus P, Killen B, Fortin K, Wrigley TV, Bennell KL, Cicuttini FM, Lloyd DG. Tibiofemoral contact forces during walking, running and sidestepping. Gait Posture; 2016: 49, 78-85.

34. Muraki S, Oka H, Akune T, Mabuchi A, En-Yo Y, Yoshida M, Saika A, Suzuki T, Yoshida H, Ishibashi H, Yamamoto S. Prevalence of radiographic knee osteoarthritis and its association with knee pain in the elderly of Japanese population-based cohorts: the ROAD study. Osteoarthr Cartil; 2009: 17, 1137-1143.

35. Krajnc Z, Vogrin M, Rečnik G, Crnjac A, Drobnič M, Antolič V. Increased risk of knee injuries and osteoarthritis in the non-dominant leg of former professional football players. Wien Klin Wochenschr; 2010: 122, 40-43. 


\section{List of figures}

Figure 1: Tibiofemoral compartment loads as a function of sex, side and movement; grey = male $\&$ black $=$ female $($ a. medial compartment force during the run movement, b. medial force during the cut movement, c. lateral force during the run movement $\&$ d. lateral force during the cut movement). 


\section{Figure}

Figure
Click here to download high resolution image
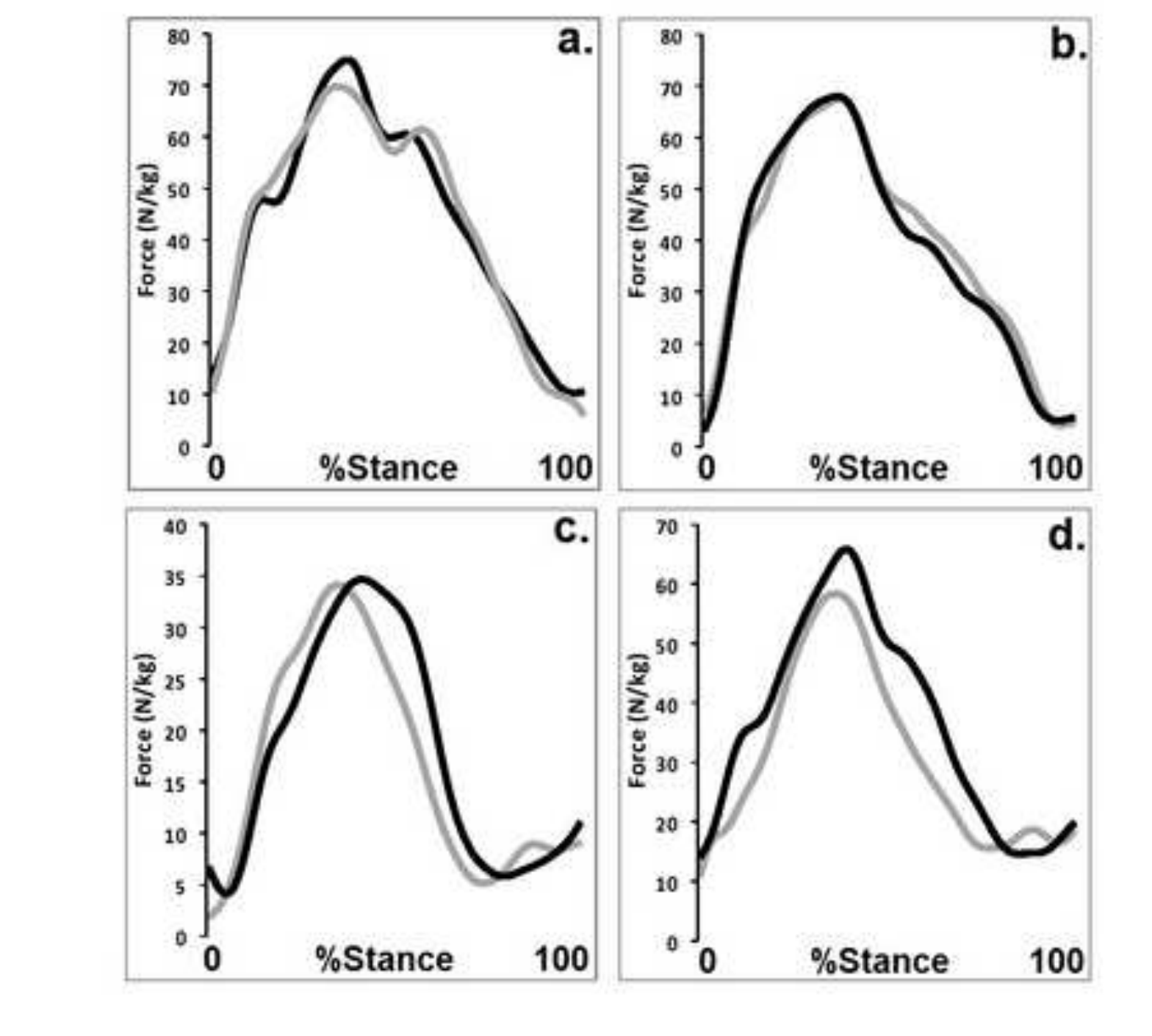

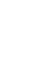

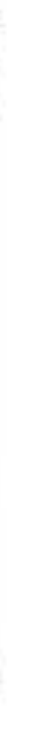


Table 1a: Medial and lateral tibiofemoral loads (Mean, SD \& 95\%Cl) for male athletes as a function of movement and side.

\begin{tabular}{|c|c|c|c|c|c|c|c|c|c|c|c|c|}
\hline & \multicolumn{12}{|c|}{ Male } \\
\hline & \multicolumn{6}{|c|}{ Run } & \multicolumn{6}{|c|}{ Cut } \\
\hline & \multicolumn{3}{|c|}{ Medial } & \multicolumn{3}{|c|}{ Lateral } & \multicolumn{3}{|c|}{ Medial } & \multicolumn{3}{|c|}{ Lateral } \\
\hline & Mean & $S D$ & $95 \% \mathrm{Cl}$ & Mean & $S D$ & $95 \% \mathrm{Cl}$ & Mean & $S D$ & $95 \% \mathrm{Cl}$ & Mean & $S D$ & $95 \% \mathrm{Cl}$ \\
\hline Maximum force $(\mathrm{N} / \mathrm{kg})$ & 71.32 & 22.48 & $58.88-83.77$ & 33.49 & 11.47 & $27.14-39.85$ & 69.30 & 13.78 & $61.67-79.93$ & 59.17 & 15.20 & $50.75-67.58$ \\
\hline Average load rate $(\mathrm{N} / \mathrm{kg} / \mathrm{s})$ & 989.89 & 415.41 & 593.71-1386.07 & 436.02 & 175.50 & $338.83-533.22$ & 758.41 & 335.22 & $572.78-944.05$ & 596.93 & 208.38 & $481.54-712.33$ \\
\hline Instantaneous load rate ( $\mathrm{N} / \mathrm{kg} / \mathrm{s})$ & 2102.12 & 645.40 & $1412.44-2791.80$ & 971.14 & 384.43 & $758.25-1184.03$ & 1786.23 & 627.24 & $1438.88-2133.59$ & 1465.42 & 431.49 & $1226.47-1704.37$ \\
\hline Force integral (N/kg·s) & 8.59 & 2.70 & $7.09-10.08$ & 3.49 & 1.27 & $2.78-4.19$ & 9.50 & 2.47 & $8.13-10.87$ & 8.02 & 2.73 & $6.51-9.53$ \\
\hline
\end{tabular}

Table 1b: Medial and lateral tibiofemoral loads (Mean, SD \& 95\% Cl) for female athletes as a function of movement and side.

\begin{tabular}{|c|c|c|c|c|c|c|c|c|c|c|c|c|}
\hline & \multicolumn{12}{|c|}{ Female } \\
\hline & \multicolumn{6}{|c|}{ Run } & \multicolumn{6}{|c|}{ Cut } \\
\hline & \multicolumn{3}{|c|}{ Medial } & \multicolumn{3}{|c|}{ Lateral } & \multicolumn{3}{|c|}{ Medial } & \multicolumn{3}{|c|}{ Lateral } \\
\hline & Mean & $S D$ & $95 \% \mathrm{Cl}$ & Mean & $S D$ & $95 \% \mathrm{Cl}$ & Mean & $S D$ & $95 \% \mathrm{Cl}$ & Mean & $S D$ & $95 \% \mathrm{Cl}$ \\
\hline Maximum force ( $\mathrm{N} / \mathrm{kg})$ & 73.85 & 12.47 & $66.95-80.76$ & 33.61 & 8.97 & $28.64-38.58$ & 69.41 & 12.98 & $62.23-76.60$ & 64.03 & 12.69 & $57.01-71.06$ \\
\hline Average load rate $(\mathrm{N} / \mathrm{kg} / \mathrm{s})$ & 932.39 & 308.59 & $761.50-1103.28$ & 388.36 & 177.28 & $290.18-485.53$ & 838.04 & 333.20 & $653.52-1022.56$ & 605.16 & 163.64 & $514.55-695.78$ \\
\hline Instantaneous load rate (N/kg/s) & 2111.01 & 646.09 & $1753.22-2468.81$ & 934.37 & 456.28 & $681.69-1187.05$ & 2011.97 & 516.47 & $1725.95-2297.98$ & 1486.46 & 381.65 & $1275.11-1697.81$ \\
\hline Force integral (N/kg·s) & 9.69 & 1.81 & $8.69-10.68$ & 3.69 & 1.41 & 2.91-4.47 & 9.43 & 2.44 & 8.08-10.79 & 8.72 & 2.55 & 7.31-10.13 \\
\hline
\end{tabular}


Table 2: Stride characteristics (Mean, SD \& $95 \% \mathrm{Cl}$ ) as a function of sex.

\begin{tabular}{|c|c|c|c|c|c|c|}
\cline { 2 - 7 } \multicolumn{1}{c|}{} & \multicolumn{4}{c|}{ Male } & \multicolumn{3}{c|}{ Female } \\
\cline { 2 - 7 } \multicolumn{1}{c|}{} & Mean & SD & $95 \% \mathrm{Cl}$ & Mean & SD & $95 \% \mathrm{Cl}$ \\
\hline Step length $(\mathbf{m})$ & 1.35 & 0.04 & $1.32-1.37$ & 1.22 & 0.04 & $1.20-1.25$ \\
\hline Steps per mile & 597.72 & 19.94 & $586.67-608.76$ & 657.49 & 21.93 & $645.34-669.93$ \\
\hline
\end{tabular}


Table 3: Medial and lateral tibiofemoral loads per mile (Mean, SD \& 95\% CI) for as a function of sex and side.

\begin{tabular}{|c|c|c|c|c|c|c|c|c|c|c|c|c|}
\hline & \multicolumn{6}{|c|}{ Male } & \multicolumn{6}{|c|}{ Female } \\
\hline & \multicolumn{3}{|c|}{ Medial } & \multicolumn{3}{|c|}{ Lateral } & \multicolumn{3}{|c|}{ Medial } & \multicolumn{3}{|c|}{ Lateral } \\
\hline & Mean & $S D$ & $95 \% \mathrm{Cl}$ & Mean & $S D$ & $95 \% \mathrm{Cl}$ & Mean & $S D$ & $95 \% \mathrm{Cl}$ & Mean & SD & $95 \% \mathrm{Cl}$ \\
\hline Force per mile (N/kg·s) & 5139.24 & 1612.54 & $4246.25-6032.24$ & 2090.92 & 772.32 & $1663.23-2518.62$ & 6381.78 & 1283.85 & 5670.81-7092.75 & 2436.47 & 969.90 & 1899.36-2973.59 \\
\hline
\end{tabular}

